\title{
The Significance of Artificial Neural Networks Algorithms Classification in the Multiple Sclerosis and its Subgroups
}

\author{
Yeliz Karaca $^{1}$, Şengül Hayta ${ }^{2}$ \\ Süleyman Şah University, Faculty of Management and Administrative Sciences, \\ Department of Economics, Istanbul, Turkey ${ }^{1}$ \\ Haliç University, Faculty of Engineering, Department of Computer Engineering, Istanbul, Turkey ${ }^{2}$
}

\begin{abstract}
The study includes three subgroups of Multiple Sclerosis, namely RRMS, SPMS and PPMS as well as healthy individuals. The purpose of this study is to diagnose Multiple Sclerosis subgroups through Magnetic Resonance Imaging and Expanded Status Disability Scale. MRI and EDSS data belong to 139 volunteers, 120 of whom are MS patients (76 RRMS, 38 SPMS, 6 PPMS patients) and the remaining are healthy people. All subjects are between the ages of 20 and 55. Disability levels of MS symptoms are determined using Expanded Disability Status Scale. We have focused on three regions in the brain: brain stem, periventricular corpus callosum, and upper cervical regions. EDSS scores and number of lesions in these three regions are considered as the parameters of the ANN algorithms to determine the subgroups of the disease. The empirical results are examined taking two aspects into consideration. One of them is MRI and the other is EDSS data. These two elements are applied onto the input of Artificial Neural Networks Algorithms that are Feed Forward Back Propagation, Learning Vector Quantization and Radial Basis Function. The significance of these variables for the diagnosis of MS subgroups has been revealed as a result of this study in which algorithm has been utilized.
\end{abstract}

Keywords: Multiple Sclerosis, Magnetic Resonance Imaging, Expanded Disability Status Scale, Feed Forward Back Propagation, Learning Vector Quantization, Radial Basis Function.

\section{INTRODUCTION}

Multiple Sclerosis (MS) is a chronic autoimmune central nervous system (CNS) disease that is characterized by inflammation, demyelination and axonal damage [1]. The myelin and olgondendrosit, nerve cell and axon are harmed accordingly. The causes of MS are not known thoroughly for sure so the disease can neither be prevented nor cured. Researchers have worked with interfaces to make the designing of the diagnosis of MS disease easier and understandable. By using these interfaces, which are Magnetic Resonance Imaging (MRI), Expanded Disability Status Scale (Expanded Disability Status Scale (EDSS), Cerebrospinal Fluid (CSF), etc. [2], it has been possible to diagnose the disease. The number of lesions and lesion size are determined by magnetic resonance images while patient's range of motion can be determined by means of EDSS score scale.

The performance of the neural networks based on the classifiers have been compared with that of the human experts and of the Bayesian classifier. The ability of the Multi Layer Perceptron (MLP) classifier has been far better than that of the Bayesian classifier in Artificial Neural Networks [3]. MRI data of 29 MS patients and 19 healthy people (MRI1, MRI2, MRI3 belonging to 3 different years) has been applied to decision tree classifier for RRMS, SPMS, PPMS. Relevant experiment results have been found to be $89.36 \%, 85.10 \%$ and $93.61 \%$ for MRI1, MRI2 and MRI3, respectively [4]. Among the 38 patients with RRMS and 18 SPMS, 41 of them are female while 15 of them are males. Using the lesion counts from MR data, the analysis thereof has been performed on negative binomial model. $66.6 \%$ of achievement has been gained as a result of the modeling [5].

The diagnosis of MS subgroups is a complicated Forty-nine slices with T1-weighted, T2-weighted, and biomedical problem which has captured a great deal of fluid-attenuated inversion recovery images have been attention over the past years regarding the link between examined from six examinations of three MS patients lesion counts and the behavior of lesion over time, which can be computed by machine learning algorithms. Literature review of significant and recent studies prove that the effective detection of MS subgroups has been possible through Magnetic Resonance Imaging (MRI), Expanded Disability Status Scale (EDSS), Cerebrospinal fro Fluid (CSF) and etc. Most researchers have proposed detection of MS attack through different types of machine learning algorithms. The data classification has been performed by stimulating nerves in the brain stem.

including 168 MS lesions for all candidate regions being classified into true positive and False Positive (FP) candidate regions by the use of a support vector machine. The detection sensitivity for MS lesions increased from 64.9 to $75.0 \%$ but the number of FPs per slice decreased from 19.9 to 4.4 [6]. In the earlier study of the authors, lesion counts and EDSS scores have been used based on MRI-1, MRI-2 and MRI-3 data belonging to 120 MS patients (76 RRMS, 38 SPMS, 6 PPMS patients) and 19 healthy individuals. While forming the data set, the lesion 
counts in the common lesion sizes of MRI-1, MRI-2, MR imaging were caught by MRI devices (Magnetom MRI-3 data of the patients were used as shared data the Siemens Medical Systems, Intera Achieva - Philips or/and lesion diameters with same value in the MRI-1, MRI-2, GE Healthcare) with 1,5 tesla power. MRI obtained MRI-3 data of the patients were taken as common. While outside Hacettepe Hospital were uploaded by compact forming the dataset, patients with a $1 \mathrm{~mm}$ radius in MRI-1, discs (CD) to PACS (Picture Achieving and MRI-2 as well as in MRI-3 have been handled. In other Communication System). Lesions were counted within words, for 3 MRI data with the same radius has been millimeter ( $\mathrm{mm}$ ) units measures using turbo spin echo handled [7]. Achievement has been obtained as a result (TSE) sequences. Lesion information taken from three while carrying out the training through Feed Forward areas, namely brain stem, corpus callosum, periventricular Back Propagation (FFBP) and Learning Vector area and upper cervical area. Magnetic Resonance Quantization (LVQ) for different data set (Data Set 1: Imaging (MRI) information which was read for three 139X120, Data Set 2 : 139x121) [7]. 90\% and 92\% test zones, lesion changes (increase/decrease in number, size) achievement results have been received for FFBP were calculated $[11,14]$. An example of healthy individual algorithm in Data Set 1 and LVQ algorithm, respectively. MRI data is shown in Fig.1.. Fig. 2 shows MRI data with For Data Set 2, the test achievement score is $99.75 \%$ for lesions that suffers from MS.

FFBP algorithm and $98 \%$ for LVQ algorithm. For this study, the group for Data Set 1 and Data Set 2 has been expanded for the patient subjects, which means the lesion diameters in the same lesion size constitute data of the patients. For this reason, the size of the data set used in this study is nearly twice as much as that of the study (Data Set 1: 139x228, Data Set 2:139x229) [7].

In this study, Multiple Sclerosis (MS) subgroups have been analyzed using different Artificial Neural Network algorithms such as Feed Forward Back Propagation Algorithm (FFBP), Learning Vector Quantization (LVQ), Radial Basis Functions (RBF). For this purpose, data of 120 MS patients (76 RRMS, 38 SPMS, 6 PPMS patients) and 19 healthy patients (classified by gender) is used in our experiment. Magnetic Resonance Imaging (MRI) data and Expanded Disability Status Scale (EDSS) data are applied onto the input of the algorithms. There are 4 classes that are Healthy, RRMS (Remitting Relapsing Multiple Sclerosis), SPMS (Secondary Progressive Multiple Sclerosis) and PPMS (Primer Progressive Multiple Sclerosis) are subgroups of MS. Our aim is to ensure the comparison based on the accuracy error, test performance and iteration numbers according to FFBP, LVQ and RBF algorithms for these 4 classes.

\section{MATERIAL AND METHODS}

The aim of this study is to contribute to diagnosis of MS subgroups. In this experiment, there are two types of data set. Data Set 1 is the number of lesion diameter (width for three different regions separately)and the other is EDSS score which is added to Data Set 1 that belongs to $120 \mathrm{MS}$ patients (76 RRMS, 38 SPMS, 6 PPMS patients) and 19 healthy patients (categorized by gender). Data Set 1 and Data Set 2 data are applied to Feed Forward Back Propagation, Learning Vector Quantization (LVQ) and Radial Basis Function (RBF) algorithms as input neurons. By using the number of lesion diameter (width for three different regions separately) and EDSS, estimate for RRMS, PPMS, SPMS subgroups and healthy patients have been obtained.

A. Magnetic Resonance Imaging(MRI)

MR imaging uses strong magnetic fields to form the image of the brain and spinal cord. MR image can reveal inflamed or damaged tissue cells in the central nervous system [8-11].

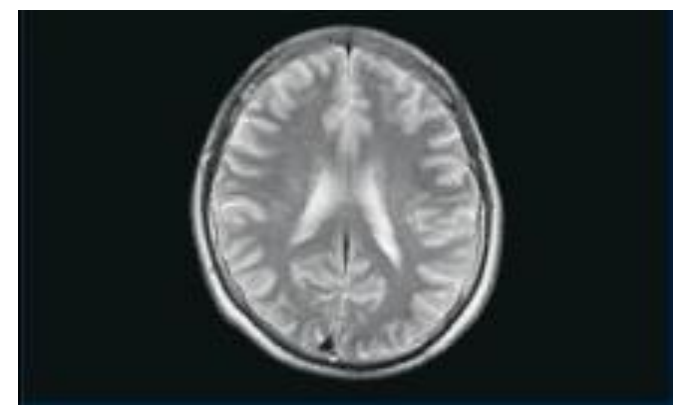

Fig.1. MRI of a Healthy Individual [11, 14].

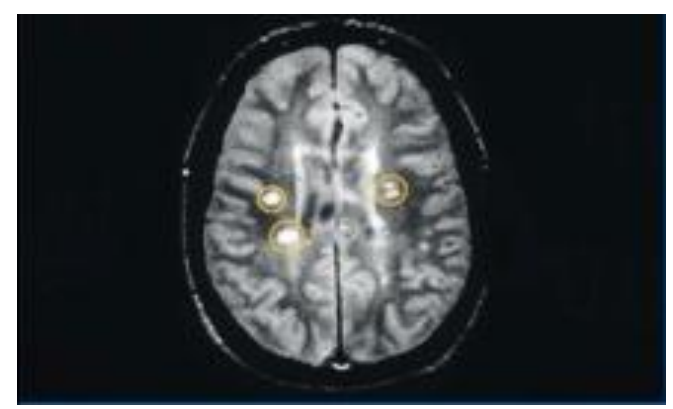

Fig.2. MRI of an Individual Suffering from MS [11, 14].

\section{B. Expanded Disability Status Scale (EDSS)}

EDSS is based on eight of the measurement on central nervous system that is known as functional systems. The scale initially includes a temporary numbness in the face and fingers or sight disturbances. The scale measures the degree of impairment in these systems. Then, the measurement is based on disability movement in walking [11 -14].

The functional systems measured by EDSS are as follows: 1. pyramidal - voluntary movement

2.brainstem - such as eye movement, sensation, facial movement, swallowing functions

3. sight

4. brain - memory, concentration, mood

5. cerebellum - the coordination of movement and balance 6. sense

7. bowel and bladder

8. other - includes fatigue.

These systems are graded based on the level of each disorder. These degrees range from 0 to 10.20 steps for EDSS are provided in the TABLE I [2, 11-15]: 
TABLE I: DESCRIPTION OF EDSS SCORES $[11,14]$.

\begin{tabular}{|c|c|}
\hline Score & Des \\
\hline 1.0 & $\begin{array}{l}\text { No disability, minimal signs in one Functional } \\
\text { System. }\end{array}$ \\
\hline 1.5 & $\begin{array}{l}\text { No disability, minimal signs in more than one } \\
\text { Functional System. }\end{array}$ \\
\hline 2.0 & Minimal disability in one Functional System. \\
\hline 2.5 & $\begin{array}{l}\text { Mild disability in one Functional System or } \\
\text { minimal disability in two of the Functional } \\
\text { Systems. }\end{array}$ \\
\hline 3.0 & $\begin{array}{l}\text { Moderate disability in one Functional System, } \\
\text { or mild disability in three or four of the } \\
\text { Functional Systems. No impairment in } \\
\text { walking }\end{array}$ \\
\hline 3.5 & $\begin{array}{l}\text { Moderate disability in one Functional System } \\
\text { and more than minimal disability in several } \\
\text { others. No impairment in walking. }\end{array}$ \\
\hline 4.0 & $\begin{array}{l}\text { Significant disability but self-sufficient up to } \\
\text { roughly } 12 \text { hours a day. Able to walk without } \\
\text { aid or rest for } 500 \mathrm{~m} \text {. }\end{array}$ \\
\hline 4.5 & $\begin{array}{l}\text { Significant disability but up and about much } \\
\text { of the day, able to work a full day, may } \\
\text { otherwise have some limitation of full activity } \\
\text { or require minimal assistance. Able to walk } \\
\text { without aid or rest for } 300 \mathrm{~m} \text {. }\end{array}$ \\
\hline 5.0 & $\begin{array}{l}\text { Disability severe enough to impair full daily } \\
\text { activities and ability to work a full day without } \\
\text { special provisions. Able to walk without aid or } \\
\text { rest for } 200 \mathrm{~m} \text {. }\end{array}$ \\
\hline 6.0 & $\begin{array}{l}\text { lking aid-cane, } \\
\text { Om with or witl }\end{array}$ \\
\hline 6.5 & $\begin{array}{l}\text { Requires two walking aids- pair of canes, } \\
\text { crutches, etc. - to walk about } 20 \mathrm{~m} \text { without } \\
\text { resting. }\end{array}$ \\
\hline 7.0 & $\begin{array}{l}\text { Unable to walk beyond approximately } 5 \mathrm{~m} \\
\text { even with aid. Essentially restricted to } \\
\text { wheelchair; though wheels self in standard } \\
\text { wheel chair and transfers alone. Up and about } \\
\text { in wheelchair some } 12 \text { hours a day. }\end{array}$ \\
\hline 7.5 & $\begin{array}{l}\text { Unable to take more than a few steps. } \\
\text { Restricted to wheelchair and may need aid in } \\
\text { transferring. Can wheel self but cannot carry } \\
\text { on in standard wheelchair for a full day and } \\
\text { may require a motorized wheelchair. }\end{array}$ \\
\hline 8.0 & $\begin{array}{l}\text { Essentially restricted to bed or chair or pushed } \\
\text { wheelchair. May be out of bed itself much of } \\
\text { the day. Retains many self-care functions. } \\
\text { Generally has effective use of arms. }\end{array}$ \\
\hline 8.5 & $\begin{array}{l}\text { Essentially restricted to bed much of day. Has } \\
\text { some effective use of arms retains some self- } \\
\text { care functions. }\end{array}$ \\
\hline 9.0 & $\begin{array}{l}\text { Confined to bed. Can still communicate and } \\
\text { eat. }\end{array}$ \\
\hline 9.5 & $\begin{array}{l}\text { Confined to bed and totally dependent. Unable } \\
\text { to communicate effectively or eat/swallow. }\end{array}$ \\
\hline 10.0 & \\
\hline
\end{tabular}

\section{MS Subgroups and Patient Details}

In this study, three subgroups of MS have been examined.
Relapsing Remitting MS) (RRMS): $25 \%$ of MS patients belong to this group. At its initial phase it resembles the benign type. Following the attacks, recovery can be seen. There are complete or nearly complete recovery periods after the acute attacks. Even so some sequels can remain after recurring attacks. Attacks might last for weeks or months. No progress is observed between the attacks [2, 8 $-10,14]$.

Secondary Progressive MS (SPMS): Its initial phase resembles that of Relapsing Remitting MS. Following an early period lasting nearly five or six years, the secondary progressive period starts. Following a period with attacks and recoveries, the picture is characterized by a time when the number of attacks decreases, recovery is at a low level and disability incrementally increases [2, 8 -10, 14].

Primary Progressive MS (PPMS): In this subgroup, generally no recovery is observed.Since the initial phase, the disease progresses either slowly or rapidly Common problems include spastic paraparesis, cerebellar ataxia, urinary incontinence $[2,8-10,14]$.

139 individuals are included in our study. They were taken into observation in Hacettepe University Medical Faculty Neurology and Radiology Department in Primer Magnetic Resonance Imaging Center, Ankara, Turkey and were diagnosed with clinical Multiple Sclerosis disease based on McDonald Criteria [2, 13, 15].

A total of 120 patients (made up of 32 males and 88 females (76 RRMS, 38 SPMS, 6 PPMS patients), and 19 healthy individuals without any complaints or drug use history were included. The control group included the healthy ones. For the experiment group multiple sclerosis patients aged between 19 and 55 were selected.

\section{METHODOLOGY}

If the data is not linearly separable like our proposed features extracted from MRI, a kernel function transforms the nonlinear data into a higher-dimensional space in which the nonlinear data are linearly separable. Statistical methods are not enough to classify the nonlinear data. Artificial Neural Network algorithms become appropriate methods for such problems. In addition, they are widely used to address a variety of learning tasks for classification.

In our experiment, Data Set 1 include only MRI data (the number of lesion diameter from MRI1, MRI2, and MRI3). Data Set 2 include both width for three different regions separately MRI data number of lesion diameter and EDSS score. This study indicates the importance of EDSS score for the diagnosis of the attacks through learning performance. In our experiment, our data sets are obtained based on these three aspects which are Feed Forward Back Propagation, Learning Vector Quantization algorithms accuracy error, test performance and iteration numbers. Input data sets are presented in TABLE II.

\section{TABLE II: INPUT DATA SETS}

\begin{tabular}{ll}
\hline Data Set 1 & $139 \times 227$ \\
\hline Data Set 2 & $139 \times 228$ \\
\hline
\end{tabular}




\section{Artificial Neural Network Algorithm}

Generally, Artificial Neural Networks (ANN) classifier simulates like the human brain. ANN algorithm is an effective tool for calculation and data mining since learning and generalization encountered in the process of training or learning is produced as the inputs of ANN to come up with appropriate responses [16]. BackPropagation (BP) is a specific technique for implementing weight for a multilayered perceptron (MLP). The basic idea is to efficiently compute partial derivatives of an approximating function realized by the network with respect to all the processing element (or neuron) of the adjustable weight vector for a given value of input vector.

Owing to nonlinear activation functions, it can be easily classified as nonlinear data [18]. Since MLP structure with Back Propagation algorithm proves to be an appropriate method for classification. Moreover, it can be used for the detection of Multiple Sclerosis attacks. Based on Data Set 1 is the number of neurons of input layer is 139x227 (the number of lesion diameter), for Data Set 2 the number of neurons of input layer neuron matrix is 139x228(the number of lesion diameter and EDSS scores).

TABLE III shows, the neuron number of output layer neuron is 4 that classified into RRMS (labeled 0 for classification), PPMS (labeled - 1 for classification), SPMS (labeled 1 for classification), and Healthy (labeled 2 for classification) for both data sets.

\section{TABLE III: FEATURE EXTRACTED FROM MR IMAGES AND REPRESENTATION OF CLASSES AND EDSS.}

\begin{tabular}{|l|l|}
\hline $\begin{array}{l}\text { Feature } \\
\text { Explanation }\end{array}$ & Explanation \\
\hline EDSS & ranges between 1 and 10 \\
\hline RRMS & Integer Number (0) \\
\hline PPMS & Integer Number (-1) \\
\hline SPMS & Integer Number (1) \\
\hline Healthy & Integer Number (2) \\
\hline Lesions & $\begin{array}{l}\text { the number of lesion diameter that } \\
\text { has formed in three different parts of } \\
\text { the brain }\end{array}$ \\
\hline
\end{tabular}

Feed Forward Back Propagation Algorithm

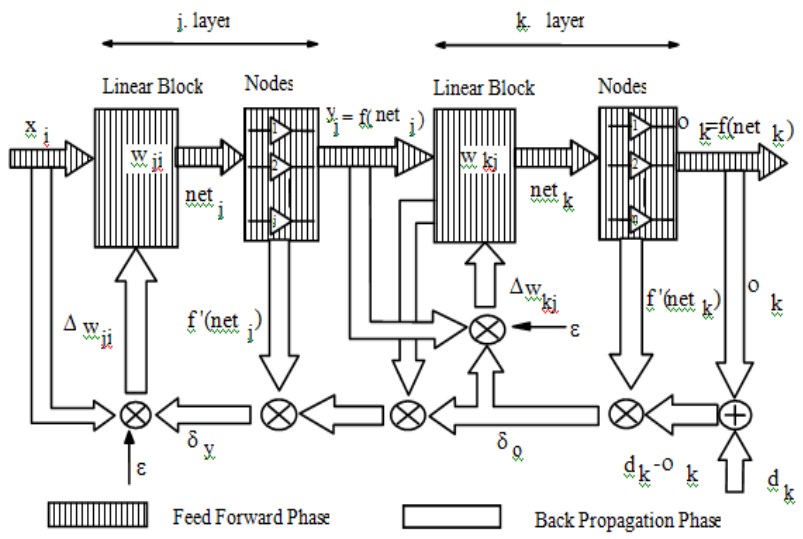

Fig. 3. Block Diagram for Feed Forward Back Propagation Algorithm [17 - 18].
Feed forward back propagation system has large number of hidden layers. The process is repeated from the previous layer corrected by subtracting process error signals. Consequently, the output level depends on the starting weight of the weight correction processing in the reverse direction and continues until it reaches the input level. The resulting system makes mistakes, but continues processing until the desired learning of something new from this error [17 - 18, 20 - 21]. Feed Forward Back Propagation principle is as in Fig. 3..

According to algorithm;

Step 1: Network architecture is defined and weighted start with some random small numbers, and they presented the first entry to the network. Here in the m-dimensional input patterns are entered [17-18],

$$
\mathrm{x}_{\mathrm{i}}=\left[\mathrm{x}_{1}, \mathrm{x}_{2}, \ldots, \mathrm{x}_{\mathrm{m}}\right]^{\mathrm{T}}
$$

Step 2: Similarly, the desired output layer is n-dimensional patterns $d_{k}=\left[d_{1}, d_{2} \ldots d_{n}\right]^{T}$. In our experiment $m$ is 227 for Data Set1 and 228 for Data Set2, $\mathrm{n}$ is output layer node number that is 4. [n= $n$ RRMS, SPMS, PPMS, Healthy $\}$ ].

Step 3: The value of $x$ the output values of the neurons in layer $\mathrm{i}$ corresponds to the total input layer neuron $\mathrm{j}$ [17 $18]$

$$
n e t_{j}=\sum_{i=1}^{m} w_{j i} \cdot x_{i} \quad \text { (from i. node to } \mathrm{j} \text {. node) }
$$

Step 4: $\mathrm{j}^{\text {th }}$ neuron output is in the hidden layer [17- 18]

$$
\mathrm{y}_{\mathrm{j}}=\mathrm{f}_{\mathrm{j}}\left(\text { net }_{\mathrm{j}}\right), \quad \mathrm{j}=1,2, \ldots, \mathrm{j}
$$

Step 5: $\mathrm{f}_{\mathrm{j}}$ is the transfer function. The total input is in the output layer of $\mathrm{k}$ neuron. net ${ }_{k}$ of each neuron in the input layer is calculated. By making the calculated value passing from the threshold value determined in the transfer function, error rate is calculated as seen in Step 6 [17 - 18].

$$
n e t_{k}=\sum_{j=1}^{J} w_{k j} \cdot y_{j}
$$

Step 6: Output of network is compared with the real output and error is calculated. These operations are iterated until the error rate gets the minimum value (based on the square error formula provided in Step 7). If the error rate does not change, the class label of the input node is assigned [17 - 18].

$$
\mathrm{e}_{\mathrm{k}}=\left(\mathrm{d}_{\mathrm{k}}-\mathrm{o}_{\mathrm{k}}\right)
$$

Step 7: The total square error is calculated for each pattern [17 - 18]:

$$
E=\frac{1}{2} \sum_{k}\left(d_{k}-o_{k}\right)^{2}
$$

\section{Learning Vector Quantization Algorithm}

Learning vector quantization (LVQ) is a method for training competitive layers that automatically learn to classify input vectors by a supervising way. The LVQ algorithm is one of the primary methods used in data quantal operation. This algorithm has been proposed by Kohonen [20] that requested information at the beginning 
of quantizing with LVQ algorithm of the same size, $n$ number of descriptors (representative) will be selected randomly for the vector. An example of whichever training set is randomly selected from the closest one. The identifier vector is determined as class better examples closer to the vector if it has been labeled by different ones with the same class as the class of subsequent steps such as selecting descriptive-vectors. This step issue is selected as the sample descriptive vector that is removed from the vector. Expression vector in each step is defined as descriptive and accurate. Accordingly, classification is performed when it is obtained after this processing, and descriptive class vector is formed. LVQ algorithm depends on the initial value. If two input vectors are very similar, the competitive layer will probably put them in the same class. There is no mechanism in a strictly competitive layer design to say whether or not any two input vectors are in the same class or in different classes. In addition, data from different classes are close to each other when these vectors in a specific region with the LVQ algorithm are stuck and thus it will not be possible to have a correct classification [21].

Generally algorithm is made up of 3 steps:

Neuron numbers are $M$, weights are $\mathrm{w}, \vec{W}_{i}$ for $i=0,1, M$ 1 , learning rate is $n$, and input vector is $L$.

Step 1: Calculate each $\mathrm{d}\left(\vec{X}, \overrightarrow{W_{m}}\right)$ feature space with Euclidean.

Step 2: Update $\overrightarrow{W_{m}}$.

$$
\overrightarrow{W_{m}} \leftarrow \overrightarrow{W_{m}}+n \times d\left(\vec{X}-\overrightarrow{W_{m}}\right)
$$

Step 3: If there is input neuron in $L$, go to Step 1, or else terminate the process.

\section{Radial Basis Function Algorithm}

Radial Basis Function (RBF) is placed in the solution space together with the appropriate width and center parameters so that the desired input-output relationship can be ensured between RBF data lying on the hidden layer and the network.

Such values generated by each of the RBF's are added by being weighted in the output layer [22 - 23].

Radial basis function is the function of the value in the center with actual value [22 - 23]

$$
\varphi(x)=\varphi(\|x\|)
$$

For each input data in the data set, each RBF in the network generates a value which is positively correlated with the distance of the data from its own center (c). Thus, it is possible to get the output generated by this input data [22 - 23].

$$
\varphi(x, c)=\varphi(\|x-c\|)
$$

Generally RBF function is:

$$
r=\left\|\mathbf{x}-\mathbf{x}_{i}\right\|
$$

As depicted in Equation 9, this is a function to calculate radius of RBF function. The input can be modeled as a vector of integer number $\mathrm{x} \in \mathrm{R}^{\mathrm{n}}$, the output of network is scalar function of the input vector $\Phi: \mathrm{R}^{\mathrm{n}} \rightarrow \mathrm{R} \Phi(\mathrm{x})=$ $\sum_{i=1}^{N} a_{i} \rho\left(\left\|x-c_{i}\right\| ; \quad N\right.$ : number of neuron, $c_{i}$ : center vector for neuron $i$ and $a_{i}$. Function is important for distance from center vector and it is named as radial basis function [22 - 23].

Although multiple radial functions exist, Gauss based radial base function is mainly utilized extensively for RBF networks [22 - 23].

$$
\varphi(r) e^{-(\varepsilon r)^{2}}
$$

For the activation function in a simple Artificial Neural Network, there will be differences based on $\mathrm{y}(\mathrm{x}), w_{i}[22-$ 23].

$$
y(x)=\sum_{i=1}^{N} w_{i} \varphi\left(\left\|x-x_{i}\right\|\right)
$$

\section{RESULTS AND DISCUSSION}

Data Set 1 and Data Set 2 multi layer perceptron (MLP) architectures are form of in Fig.4. and Fig.5.. Data Set 1 has 227 input neurons and Data Set 2 has 228 input neurons for input layer that belong to 139 individuals. Hidden layer neuron number is the same for the both data sets that is 10 . Output layer neuron number is 4 for both data sets that are SPMS, PPMS, RRMS and healthy individuals. In the experimental study, data has been separated as $70 \%$ training data, $15 \%$ test data and $15 \%$ cross validation data for both data sets that has been selected for in terms of accuracy performance.

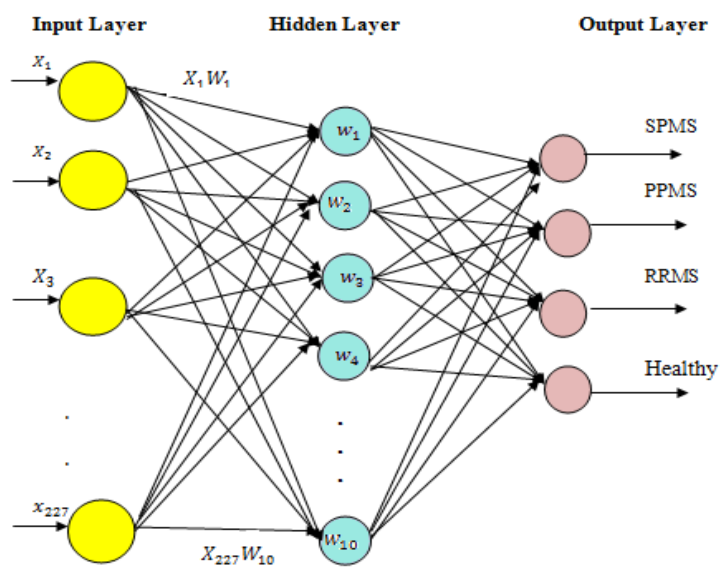

Fig.4. Feed Forward Back Propagation Algorithm Multi- Layer Perceptron Architecture Based on Data Set1 (139x227).

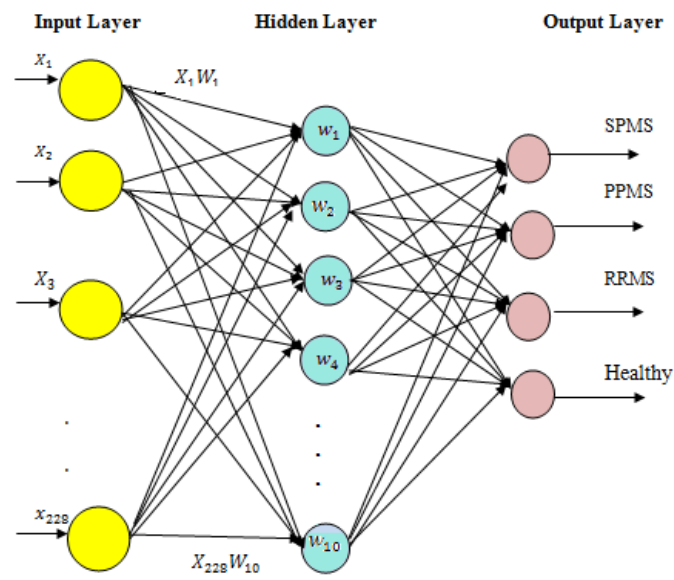

Fig.5. Feed Forward Back Propagation Algorithm Multi-Layer Perceptron Architecture Based on Data Set 2(139x228). 
Data Set 1 include only MRI1, MRI2, and MRI3 number of lesion diameter, EDSS score is added to Data Set 1 and Data Set 2 separately. These vector spaces have been applied as input for Feed Forward Back Propagation, Learning Vector Quantization, Radial Basis Function algorithms. Algorithms accuracy rates have been taken through MATLAB tool [24]. Accuracy rate of training and testing are given in TABLE IV and TABLE $\mathrm{V}$ based on Data Set 1 and Data Set 2.

\section{TABLE IV: CLASSIFICATION TEST ACCURACY} RESULTS BASED ON DATA SET 1.

\begin{tabular}{|c|c|c|c|}
\hline $\begin{array}{c}\text { ANN } \\
\text { ALGORITHMS }\end{array}$ & $\begin{array}{c}\text { Accuracy } \\
\text { Error }\end{array}$ & $\begin{array}{c}\text { Iteration } \\
\text { Number }\end{array}$ & $\begin{array}{c}\text { Test } \\
\text { Performance }\end{array}$ \\
\hline FFBP & $1 \mathrm{e}-7$ & 11 & $92.5 \%$ \\
\hline LVQ & $1 \mathrm{e}-5$ & 100 & $89 \%$ \\
\hline RBF & $1 \mathrm{e}-5$ & 100 & $98.9 \%$ \\
\hline
\end{tabular}

TABLE V: CLASSIFICATION TEST ACCURACY RESULTS BASED ON DATA SET 2.

\begin{tabular}{|c|c|c|c|}
\hline $\begin{array}{c}\text { ANN } \\
\text { ALGORITHMS }\end{array}$ & $\begin{array}{c}\text { Accuracy } \\
\text { Error }\end{array}$ & $\begin{array}{c}\text { Iteration } \\
\text { Number }\end{array}$ & $\begin{array}{c}\text { Test } \\
\text { Performance }\end{array}$ \\
\hline FFBP & $1 \mathrm{e}-5$ & 16 & $96.75 \%$ \\
\hline LVQ & $1 \mathrm{e}-4$ & 100 & $91 \%$ \\
\hline RBF & $1 \mathrm{e}-4$ & 100 & $99.9 \%$ \\
\hline
\end{tabular}

According to experimental parameters;

Mean squared error provided training rate. Transfer function is TANSIG. In our study all ANN algorithms parameters (mean squared error, epoch, transfer function, training function) are selected correspondingly. Trainlm is referred to as the training function, while learngdm is referred to as the adaption learning function. The mean squared error is referred to as the performance function, the hidden layer neuron number as 10, the transfer function as tansig, momentum as 0.001 , selected for the purpose of analysis results.

According to experiment results, the following conclusions have been drawn:

As the vector size increased, the test achievement for the disorder diagnosis increased as well based on the algorithms. The test achievement ratio of the algorithms in Data Set 1 is lower than that in Data Set 2. This has enhanced the distinctiveness and testing of the MS subgroups through the incorporation of EDSS score into DataSet 1.

As the dataset size expanded, accuracy errors decreased. In both of the datasets, a better achievement with regard to classification has been obtained compared to $\mathrm{RBF}$ algorithm. As the vector size increases, the error rate falls for FFBP algorithm and the iteration number goes up, however, the achievement score for the test also increases. The iteration number is the same in both datasets for LVQ and RBF algorithms. As the vector size increases, the disorder test achievement enhances.

\section{CONCLUSION}

In our study, the diagnosis of Healthy, RRMS, SPMS and PPMS as the subgroups of MS disease have been attempted to be determined with regards to nerve web algorithms Feed Forward Back Propagation, Learning Vector Quantization and Radial Basis Function. Two different data sets have been used in the course of this determination period. In the first data set, the number of lesion diameter, MRI scans of patients are based on the data resulted from the between the first and second MRIs scans taken in 3 years period. In Data Set $192.5 \%$ is given for the Feed Forward Back Propagation, 89\% for the Learning Vector Quantization and $98.9 \%$ for the Radial Basis Function. However, in the second data set, in addition to MRI data, EDSS scores have been added, and this has proved how important EDSS scores are for the diagnosis of MS subgroups. As can be seen in TABLE V, Data Set 2 illustrates the accuracy rate as $96.75 \%$ for the Feed Forward Back Propagation, 91\% for the Learning Vector Quantization and $99.9 \%$ for the Radial Basis Function. The increase in data set two is obvious as the numbers of variables have increased throughout our study.

EDSS score parameters is added Data Set 2 as an additional variable. Bias of the classification of the disease is done with a higher level of performance via Data Set 2 compared to Data Set 1, with 4\% for FFBP algorithm, 2\% for LVQ algorithm and 1\% for Radial Basis Function algorithm. This shows the impact of EDSS score.

This study is considered to be guiding for medical doctors to follow MS disease as well as the progress of its subgroups. In the future, increasing the number of variables (BOS liquid, vep-sep, and etc.) and having a higher estimation rate is aimed through further analyses.

\section{ACKNOWLEDGEMENT}

The authors are deeply grateful to Prof. Dr. Rana Karabudak and Hacettepe University Medical Faculty Neurology and Radiology Department in Primer Magnetic Resonance Imaging Center for providing them with the input data set and to radiologist Dr. Eray Atli and Dr. Mehmet Yorubulut, the owner of MR Imgaing Center, cooperating both in the definition of the domain knowledge and in the manual segmentation of the input dataset. Dr. Yeliz Karaca is also grateful to the Turkish Neurological Association for all their support.

\section{REFERENCES}

[1] A. Compston, I.R. McDonald, J. Noseworthy, H. Lassmann, D.H. Miller, K.J. Smith, H. Wekerle, and C. Confavreux, McAlpine's Multiple Sclerosis, $4^{\text {th }}$ ed., Churchill Livingstone Elsevier, China, 3-5, 2005.

[2] R. Karabudak, N. Ișık, and A. Siva, Multiple Sklerozda Tanı ve Tedavi Kılavuzu, Bilimsel Tıp yayınevi, Ankara, Türkiye, 5-20, 2009.

[3] H. Gutermana, Y. Nehmadi, A. Chistyakov, J. F. Soustiel, and M. Feinsod, "A comparison of neural network and bayes recognition approaches in the evaluation of the brainstem trigeminal evoked potentials in multiple sclerosis," International Journal of BioMedical Computing, vol. 43 (3) ,1996.

[4] Y. Karaca, G. Sayıc1, and R. Karabudak, "Application of decision tree for classification of $\mathrm{ms}$ diagnosis, expanded disability status scale and lesion numbers," in Proc. 7th International Image Processing \& Wavelet on Real World Applications Conference, IWW 2013, IEEE, 2013, pp. 115-129.

[5] M.P. Sormani, P. Bruzzi, D.H. Miller, C. Gasperiniive, F. Barkhof, and M. Filippi, "Modelling mri enhancing lesion counts in multiple sclerosis using a negative binomial model: implications for clinical 
trials," Elsevier, Journal of the Neurological Sciences, vol. 163, pp. 74-80, Issue 1,1999.

[6] J. Kuwazuru , H. Arimura, S. Kakeda, D. Yamamoto, T. Magome, Y. Yamashita , M. Ohki, F. Toyofuku, and Y. Korogi, "Automated detection of multiple sclerosis candidate regions in MR images: false-positive removal with use of an ANN-controlled level-set method," Japanese Society of Radiological Technology and Japan Society of Medical Physics, pp.5-105-113, 2012.

[7] Y.Karaca, S. Hayta ., "The comparison of artificial neural networks algorithms for the diagnosis of multiple sclerosis subgroups," 2 nd International Conference on Inter-disciplinary Research in Engineering, Management, Pharmacy and Science (ICIREMPS2K15), 8-14, 2015.

[8] B.Kaymakamzade, "Progresif başlangıçlı multiple skleroz hastalarında aksonal hasar belirteçlerinin klinik ve beyin omurilik sıvısı özellikleri temelinde değerlendirilmesi," Uzmanlık Tezi, Hacettepe Üniversitesi Tıp Fakültesi Nöroloji Anabilim Dalı, Ankara, Türkiye, 9-26, 2011.

[9] J. Gilroy, Basic Neurology, 3rd ed., The McGraw-Hill Companies, 225-278, 2000

[10] R. Karabudak, MS ile yaşamak, Aşina Kitaplar, Ankara, Türkiye, 11-34, 2006.

[11] Y. Karaca, O. Osman, and R. Karabudak, "Linear modeling of multiple sclerosis and its subgroups," Turkish Journal of Neurology, in Print, 2015.

[12] J. F. Kurtzke, "Rating neurologic impairment in multiple sclerosis: An expanded disability status scale (edss)," Neurology, vol. 33(11) 1444.doi:10.1212/WNL.33.11.1444, 1983.

[13] M. Gaspari, and G. Roveda et al., An Expert System for The Evaluation of EDSS in Multiple Sclerosis, Artificial Intelligence in Medicine, 187-210, 2002.

[14] Y. Karaca, "Multiple skleroz hastalığının ve alt gruplarının belirlenmesi için optimum bir matematiksel modelin oluşturulması," $\mathrm{Ph}$. D thesis, Marmara University, Turkey, 2012.

[15] L. L. McDonald, and W. Zucchini, Hidden Markov and Other Models for Discrete- valued Time Series, XVI ed., Chapman and Hall-CRC, 134-188, 2000.

[16] M.C. Bishop, Pattern Recognition and Machine Learning, Busines Dia, Llc. Springer Science, 2006.

[17] D.E. Rumelhart, and J.L. McClelland, Parallel Distributed Processing: Explorations in the Microstructure of Cognition, v.1: Foundations, MIT Press, Cambridge, MA.PDP Research Group 1986.

[18] Y.H. Pao, Adaptive Pattern Recognition and Neural Networks, Addison-Wesley Publishing Co., Reading, Mass, 1989.

[19] Y.Karaca, G. Sayıc1, "Bayesian networks for sub-groups of multiple sclerosis," in Proc. of $6^{\text {th }}$ International Image Processing \& Wavelet on Real World Applications Conference, 2012.

[20] T.Kohonen, Self- Organization and Associative Memory, $3^{\text {rd }}$ ed., Springer-Verlag, 1989

[21] T. Temel, B. Karlık, "An improved odor recognition system using learning vector quantization with a new discriminant analysis," Neural Network World, 17(4), 287 - 94, 2007.

[22] S. Chen, C.F.N. Cowan, P.M. Grant, "Orthogonal least squares learning algorithm for radial basis function networks," IEEE Transactions on Neural Networks, Vol. 2, No. 2, pp. 302-309, March 1991.

[23] M. D. Buhmann, Radial Basis Functions: Theory and Implementations, Cambridge University Press, ISBN 978-0-52163338-3, 2003

[24] The web site [Online]. Available: www.mathworks.com/products (2014)

\section{BIOGRAPHIES}

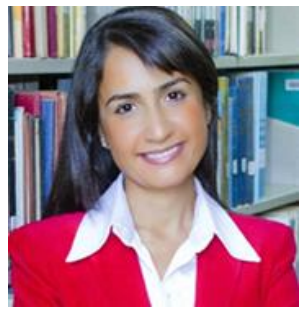

Asst. Prof . Yeliz KARACA

Yeliz Karaca was born in Aksaray, Turkey on July 13, 1977. She received a B.S degree in Mathematics from Yildiz Technical University (Istanbul, Turkey) in 2003. She got her M.Sc. degree in Theoretical Mathematics from Yeditepe University (Istanbul, Turkey) in 2007 with an honorary degree. Her Ph.D degree in Theoretical Mathematics is from Marmara University(Istanbul, Turkey) in 2012. With her dissertation titled "Constituting an Optimum Mathematical Model for the Diagnosis of Multiple Sclerosis", she has formed an optimum mathematical model for Multiple Sclerosis disease and its subgroubs for the first time. She has worked cooperatively with Hacettepe University Faculty of Medicine , Department of Neurology and Radiology in the course of the above mentioned study. She also had Neuroradiology training in School of Neuroradiology through a scholarship granted by Neurology Association (Bilkent Ankara) in 2012. She had an award for "Cooperation in the field of Neurological Sciences and Support Award" from the Turkish Neurology Association as the first mathematician in Turkey and presently she has been an honorary member of the Turkish Neurology Association. She is also a member of the Turkish Mathematicians' Association. Her area of researches are Stochastic modelling, Stochastic Processes, Probability, mathematical statistics, computational and mathematical modelling of neural systems and nonlinear integral equators and analysis, analysis of nonlinear integral equations in positive Banach spaces. Wavelet analysis and Wavelet transformations. She has worked as a lecturer, instructor, teaching and research assistant at the Department of Mathematics, in Istanbul Commerce University and in Haliç University, Istanbul, Turkey. She is presently holding an Asst. Prof. position in Süleyman Şah University.

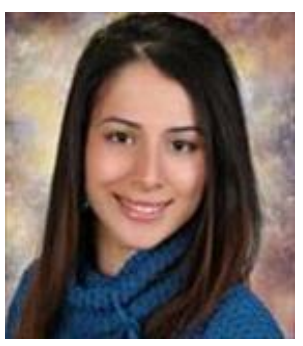

\section{Research Assistant \& Phd} Student Sengül HAYTA

Şengül Hayta was born in Malatya, Turkey on July 15, 1986. Şengül Hayta graduated from Department of Computer Engineering at Haliç University in 2009. Her master degree is from Department of Computer Engineering at Haliç University in 2011. She has worked as a research assistant of Computer Engineering at Haliç University since 2009. She is a Ph.D student in Computer Engineering at Istanbul University. She has taught courses like Data Mining, Neural Networks and Applications and Criminal Data Mining. 